Ramponi R, Blocken B. 2012. CFD simulation of cross-ventilation flow for different isolated building configurations: validation with wind tunnel measurements and analysis of physical and numerical diffusion effects. Journal of Wind Engineering and Industrial Aerodynamics 104-106: 408-418.

\title{
CFD simulation of cross-ventilation flow for different isolated building configurations: validation with wind tunnel measurements and analysis of physical and numerical diffusion effects
}

\author{
R. Ramponi ${ }^{(\mathrm{a}, \mathrm{b})}$, B. Blocken ${ }^{(\mathrm{b})} *$
}

(a) Building Environment Science \& Technology Department, Politecnico di Milano, via Bonardi 3, 20133 Milano, Italy

(b) Building Physics and Services, Eindhoven University of Technology, P.O. box 513, 5600 MB Eindhoven, the Netherlands

\section{Graphical abstract}

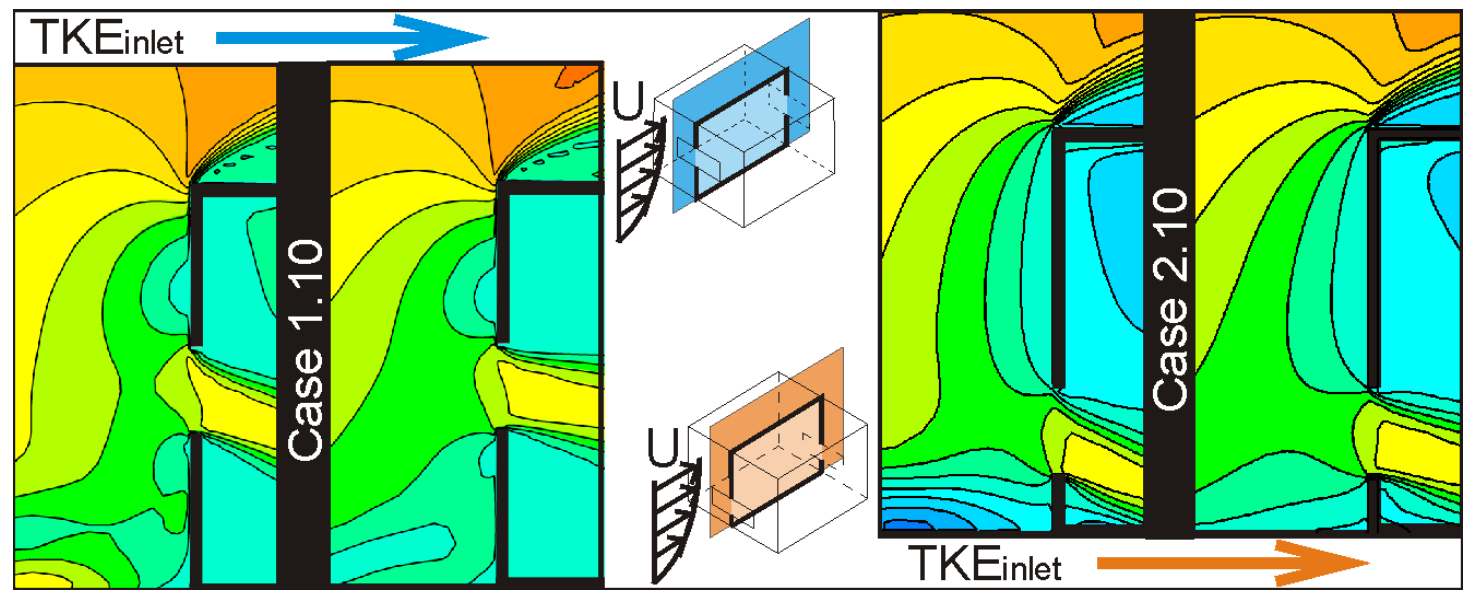

\section{Research Highlights}

- 3D steady RANS CFD simulations of natural cross-ventilation with SST k- $\omega$ model.

- Validation for different opening configurations with PIV measurements.

- Analysis of physical diffusion by variation in inlet turbulent kinetic energy

- Analysis of numerical diffusion by variations in grid and discretisation schemes

- Diffusion is very important: high-resolution grids and higher-order discretisation required.

\footnotetext{
* Corresponding author: Bert Blocken, Building Physics and Services, Eindhoven University of Technology, P.O. Box 513, 5600 MB Eindhoven, the Netherlands. Tel.: +31 (0)40 247 2138, Fax +31 (0)40 2438595

E-mail address: b.j.e.blocken@tue.nl
} 
Ramponi R, Blocken B. 2012. CFD simulation of cross-ventilation flow for different isolated building configurations: validation with wind tunnel measurements and analysis of physical and numerical diffusion effects. Journal of Wind Engineering and Industrial Aerodynamics 104-106: 408-418.

\title{
CFD simulation of cross-ventilation flow for different isolated building configurations: validation with wind tunnel measurements and analysis of physical and numerical diffusion effects
}

\author{
R. Ramponi ${ }^{(a, b)}$, B. Blocken ${ }^{(b)} *$ \\ (a) Building Environment Science \& Technology Department, Politecnico di Milano, via Bonardi 3, 20133 \\ Milano, Italy \\ (b) Building Physics and Services, Eindhoven University of Technology, P.O. box 513, 5600 MB Eindhoven, \\ the Netherlands
}

\begin{abstract}
Computational Fluid Dynamics (CFD) has become one of the most important tools for the assessment of natural cross-ventilation of buildings. To ensure the accuracy and reliability of CFD simulations, solution verification and validation studies are needed, as well as detailed sensitivity studies to analyse the impact of computational parameters on the results. In a previous study by the present authors, the impact of a wide range of computational parameters on the cross-ventilation flow in a generic isolated single-zone building was investigated. This paper presents the follow-up study that focuses in more detail on validation with wind tunnel measurements and on the effects of physical and numerical diffusion on the cross-ventilation flow. The CFD simulations are performed with the 3D steady Reynolds-Averaged Navier-Stokes (RANS) approach with the SST k- $\omega$ model to provide closure. Validation of the coupled outdoor wind flow and indoor airflow simulations is performed based on Particle Image Velocimetry (PIV) measurements for four different building configurations. The analysis of numerical diffusion effects is performed in two parts. First, the effect of physical diffusion is analysed by changing the inlet profiles of turbulent kinetic energy within a realistic range. Second, the effect of numerical diffusion is investigated by changing the grid resolution and by applying both first-order and second-order discretisation schemes. The results of the validation study show a good to very good agreement for three of the four configurations, while a somewhat less good agreement is obtained for the fourth configuration. The results of the diffusion study show that the effects of physical and numerical diffusion are very similar. Along the centreline between the openings, these effects are most pronounced inside the building, and less pronounced outside the building. The velocity-vector fields however show that increased physical and numerical diffusion decreases the size of the upstream standing vortex and increases the spread of the jet entering the buildings. It is concluded that diffusion is an important transport mechanism in cross-ventilation of buildings, and that special care is needed to select the right amount of physical diffusion and to reduce the numerical diffusion, by using high-resolution grids and by using at least second-order accurate discretisation schemes.
\end{abstract}

Keywords: Computational Fluid Dynamics (CFD); complex airflow; experimental validation; artificial diffusion; numerical dissipation; parametric analysis

\section{Introduction}

Natural ventilation of buildings is an important approach towards a sustainable and energy-efficient built environment. Natural ventilation can be driven by wind-induced pressure differences or by thermally-induced pressure differences, or by a combination of both (e.g. Linden 1999, Hunt and Linden 1999, Li and Delsante 2001, Heiselberg et al. 2004, Larsen and Heiselberg 2008, Chen 2009, van Hooff and Blocken 2010a). A distinction can be made between cross-ventilation and single-sided ventilation (e.g. Jiang and Chen 2002, Jiang

\footnotetext{
* Corresponding author: Bert Blocken, Building Physics and Services, Eindhoven University of Technology, P.O. Box 513, 5600 MB Eindhoven, the Netherlands. Tel.: +31 (0)40 247 2138, Fax +31 (0)40 2438595

E-mail address: b.j.e.blocken@tue.nl
} 
et al. 2003, Evola and Popov 2006, Tablada et al. 2009, Caciolo et al. 2012). In the present paper, the focus will be on cross-ventilation.

In the past decades, Computational Fluid Dynamics (CFD) has become one of the most important tools in ventilation research (Chen 2009). This is also true for natural cross-ventilation of buildings, as illustrated by the very large number of CFD studies that have been published in the past 20 years (e.g. Kato et al. 1992, Straw et al. 2000, Jiang and Chen 2001, Jiang et al. 2003, Murakami et al. 2004, Heiselberg et al. 2004, Mochida et al. 2005, 2006, Seifert et al. 2006, Wright and Hargreaves 2006, Hu et al. 2008, Stavrakakis et al. 2008, Evola and Popov 2009, van Hooff and Blocken 2010a, 2010b, Norton et al. 2010, Kobayashi et al. 2010, Nikas et al. 2010, Ramponi and Blocken 2012).

In CFD simulations, accuracy and reliability are main concerns. It is widely recognized that CFD simulations can be very sensitive to the large number of computational parameters that have to be set by the user. Therefore, CFD verification and validation studies are imperative, as well as detailed sensitivity studies that can provide guidance in the selection of computational parameters for future CFD studies. Recently, an extensive sensitivity study was performed by Meroney (2009). Later, the present authors have performed a detailed review of the literature, followed by an extensive sensitivity study for a generic isolated building (Ramponi and Blocken 2012). The impact of a wide range of computational parameters was investigated, including the size of the computational domain, the resolution of the computational grid, the inlet turbulent kinetic energy profile of the atmospheric boundary layer, the turbulence model, the order of the discretisation schemes and the iterative convergence criteria. It should be noted that this study only focused on the Reynolds-Averaged Navier-Stokes (RANS) approach. This was motivated by the fact that, although Large Eddy Simulation (LES) is intrinsically more accurate than RANS, the RANS approach is still most often used. Indeed, a recent review of CFD cross-ventilation studies by the authors (Ramponi and Blocken 2012) indicated that out of 39 studies analysed, 32 were based on the RANS approach, 3 on Large Eddy Simulation (LES) and 1 on Detached Eddy Simulation (DES), while among the remaining 3 studies, 2 studies applied both RANS and LES and 1 applied RANS, LES and DES.

The previous sensitivity study by the authors however only focused on a single building configuration, and it did not focus in detail on the effects of physical and numerical diffusion on the simulation results. Numerical diffusion refers to the fact that the simulated airflow exhibits a higher diffusivity than the real airflow. It is not a real phenomenon, but its effect on the flow is the same as that of increasing the real (physical) diffusivity. Numerical diffusion arises from truncation errors due to the discretisation of the governing flow equations. The amount of numerical diffusion is directly related to the resolution of the computational grid. Spurious numerical diffusion is also known to occur when first-order discretisation schemes are used. The effect of numerical diffusion will be largest when the real diffusion is small, i.e. when the flow is dominated by convection. It is interesting to note that the importance of limiting numerical diffusion is emphasised by the Journal of Fluids Engineering Editorial Policy (ASME 2011), incited by contributions by Roache et al. (1986) and Freitas (1993), which demands at least formally second-order accurate spatial discretisation. For this reason, also the best practice guidelines for CFD in general (Casey and Wintergeste 2000) and CFD in environmental wind engineering (Franke et al. 2007, Tominaga et al. 2008) prescribe the use of second-order accurate discretisation schemes.

The present paper provides a validation study of cross-ventilation flow for four different isolated building configurations. The simulation results are compared with Particle Image Velocity (PIV) wind tunnel measurements by Karava et al. (2011). The present paper also provides an evaluation of the effects of physical and numerical diffusion on cross-ventilation flow in these four building configurations. Coupled CFD simulations of outdoor wind flow and indoor airflow are performed with the 3D steady RANS approach and the SST k- $\omega$ turbulence model (Menter, 1994). This turbulence model was chosen because of its superior performance compared to other RANS models for cross-ventilation of a simple isolated building, as shown in the sensitivity study by Ramponi and Blocken (2012). The amount of physical diffusion is varied by changing the inlet profiles of turbulent kinetic energy within a realistic range. The amount of numerical diffusion is varied by changing the grid resolution and by applying both first-order and second-order discretisation schemes.

\section{Wind tunnel experiments}

Wind tunnel measurements with Particle Image Velocimetry (PIV) were performed to analyse cross-ventilation flow of simplified building models (Karava et al. 2011). The experiments were performed in the open-circuit Boundary Layer Wind Tunnel of Concordia University in Montreal (Stathopoulos, 1984). The wind tunnel is 12 $\mathrm{m}$ long and has a cross-section of $1.8 \times 1.8 \mathrm{~m}^{2}$ but the measurements were performed in a small extension of the wind tunnel added downstream of the turntable. The building models, at a scale of 1:200, were built from a 2 mm cast transparent polymethylmethacrylate (PMMA) sheet and had dimensions of $\mathrm{W} \times \mathrm{D} \times \mathrm{H}=100 \mathrm{x} 100 \mathrm{x}$ 
$80 \mathrm{~mm}^{3}$ (20 x $20 \times 16 \mathrm{~m}^{3}$ in full scale) (Figure 1). Different configurations were obtained by changing the mutual position of the openings at the bottom $(\mathrm{h}=20 \mathrm{~mm})$, centre $(\mathrm{h}=40 \mathrm{~mm})$ and top $(\mathrm{h}=60 \mathrm{~mm})$ of the windward and leeward walls of the building model. The area of openings was also varied to test different wall porosities (w.p.), i.e. different ratios between the areas of the openings and the areas of the facade walls. A fixed opening height of $18 \mathrm{~mm}$ ( $3.6 \mathrm{~m}$ in full scale) was used, while the opening width was varied between $22 \mathrm{~mm}$ (4.4 $\mathrm{m}$ in full-scale; w.p. $=5 \%), 46 \mathrm{~mm}(9.2 \mathrm{~m}$ in full-scale; w.p. $=10 \%)$ and $88 \mathrm{~mm}(17.6 \mathrm{~m}$ in full-scale; w.p. $=20 \%$ ). In this paper, the configurations with the openings at the centre (configuration 1) and the bottom (configuration 2) of the opposite walls are considered, with wall porosities of 5\% (Cases 1.05 and 2.05) and 10\% (Case 1.10 and 2.10), as shown in Figure 1.

The measurements were performed with the model placed in the extension of the wind tunnel with the openings perpendicular to the streamwise direction. An upstream roughness profile corresponding to open terrain $\left(\mathrm{z}_{0}=0.005 \mathrm{~m}\right.$ in full scale) was obtained by placing extruded polystyrene (XPS) cubes far upstream and a carpet less far upstream of the wind-tunnel turntable (Karava 2008). The incident vertical profiles of mean wind speed and streamwise turbulence intensity were measured with a hot-film probe at the building position. A reference mean wind speed $\mathrm{U}_{\text {ref }}=6.97 \mathrm{~m} / \mathrm{s}$ and a streamwise turbulence intensity of $10 \%$ were reported at building height $(\mathrm{H}=80 \mathrm{~mm})$, while the turbulence intensity was about $17 \%$ near the ground level $(12 \mathrm{~mm})$ and about $5 \%$ at gradient height $(738 \mathrm{~mm})$. Figure 2 shows the measured mean wind speed and turbulence intensity profile, as well as the fitted logarithmic law, which will be used as inlet boundary conditions in the simulations in this paper. The values in the $\log$ law are $\mathrm{z}_{0}=0.025 \mathrm{~mm}$ (reduced scale) and $\mathrm{u}^{*}=0.363 \mathrm{~m} / \mathrm{s}$. The PIV measurements were conducted in the vertical centreplane for both configuration 1 and 2, as indicated in Figure 1. Further information about the measurements can be found in Karava (2008), Karava et al. (2011) and Karava and Stathopoulos (2011).

\section{CFD simulations: computational settings and parameters}

\subsection{Computational domain and grid}

The CFD simulations were performed at model scale. The dimensions of the computational domain were determined based on the existing best practice guidelines (Franke et al. 2007, Tominaga et al., 2008), except for the upstream length (i.e. distance between inlet plane and windward building facade), which was taken equal $3 \mathrm{H}$ instead of $5 \mathrm{H}$, in order to limit the development of unintended streamwise gradients (Blocken et al. 2007a, 2007b). A test simulation has shown that using $3 \mathrm{H}$ is justified, because the extent of the upstream disturbance of the flow pattern by the building is less than $3 \mathrm{H}$. The resulting dimensions of the domain were Width $\mathrm{x}$ Depth $\mathrm{x}$ Height $=0.9 \times 1.54 \times 0.48 \mathrm{~m}^{3}\left(180 \times 308 \times 96 \mathrm{~m}^{3}\right.$ in full scale $)$. The upstream distance between inlet plane and windward building facade is $0.24 \mathrm{~m}(3 \mathrm{H})$, while the downstream distance between leeward building facade and outlet plane is $1.2 \mathrm{~m}(15 \mathrm{H})$. The distance between the side walls of the building and the side planes of the domain is $0.4 \mathrm{~m}(5 \mathrm{H})$ on both sides. A fully structured grid was built. It was first constructed in the ground plane and then extruded in the vertical direction following the surface-extrusion technique presented by van Hoof and

Blocken (2010a). This technique, where the grid is first constructed in the ground plane, allowed a better control of the stretching ratio from the very fine grid required due to the thickness of the walls $(2 \mathrm{~mm}$ thin in model scale) and the coarser grid along the edges of the domain. The stretching ratio was kept under a value of 1.2 in the surroundings of the building model. A grid-sensitivity analysis was conducted for Case 1.10 to ensure a sufficient degree of grid independence of the results. Three grids were made by increasing the resolution with about a factor 2, from Grid A (144,969 cells) over Grid B (314,080 cells) to Grid C (575,247 cells) (Fig. 3a-c). The minimum cell sizes are $1.36 \mathrm{~mm}^{3}, 1.02 \mathrm{~mm}^{3}$ and $0.51 \mathrm{~mm}^{3}$ for Grid A, B and C, respectively. The results obtained on these three grids are compared in terms of the streamwise wind speed ratio $\left(U / U_{\text {ref }}\right)$ along the centreline of the openings (Fig. 3d). Note that $U$ is the streamwise component of the 3D velocity vector, and that $\mathrm{U}_{\text {ref }}=6.97 \mathrm{~m} / \mathrm{s}$ is the reference wind speed in the incident profile at building height $(\mathrm{H}=80 \mathrm{~mm})$. Figure $3 \mathrm{~d}$ indicates large differences between grid $\mathrm{A}$ and grid $\mathrm{B}$, but a relatively small difference between grid $\mathrm{B}$ and grid C. This indicates that the resolution of the finer grid (Grid C) is suitable. Therefore a similar grid resolution was also used for the remaining cases (Case 1.05, Case 2.05 and Case 2.10).

\subsection{Boundary conditions}

The measured vertical profiles of mean wind speed $U$ and streamwise turbulence intensity $I_{u}$ are used to define the inlet boundary conditions for the CFD simulations. The inlet profile of mean wind speed is described by the logarithmic law (Eq. 1), where $\mathrm{u}^{*}$ is the friction velocity, $\kappa$ the von Karman constant equal to 0.42 and $\mathrm{z}$ the height-coordinate. 
$\mathrm{U}(\mathrm{z})=\frac{\mathrm{u}^{*}}{\kappa} \ln \left(\frac{\mathrm{z}+\mathrm{z}_{0}}{\mathrm{z}_{0}}\right)$

To determine the turbulent kinetic energy, information about the standard deviations of the turbulent fluctuations in the three directions is needed:

$\mathrm{k}(\mathrm{z})=\frac{1}{2}\left({\sigma_{\mathrm{u}}^{2}}_{\mathrm{z}}(\mathrm{z})+\sigma_{\mathrm{v}}^{2}(\mathrm{z})+\sigma_{\mathrm{w}}^{2}(\mathrm{z})\right)$

Often however, only $\sigma_{u}{ }^{2}$ is measured, which is related to the longitudinal turbulence intensity: $I_{u}=\sigma_{u} / U$. For the other two components, different assumptions can be made, which yield different values for the turbulent kinetic energy:

Assumption 1: $\sigma_{\mathrm{u}}{ }^{2}>>\sigma_{\mathrm{v}}{ }^{2} \approx \sigma_{\mathrm{w}}{ }^{2}$, which yields:

$\mathrm{k}(\mathrm{z})=\frac{1}{2}\left(\mathrm{I}_{\mathrm{u}}(\mathrm{z}) \mathrm{U}(\mathrm{z})\right)^{2}$

Assumption 2: $\sigma_{\mathrm{u}}{ }^{2} \approx{\sigma_{\mathrm{v}}}^{2}+{\sigma_{\mathrm{w}}}^{2}$, which yields:

$\mathrm{k}(\mathrm{z})=\left(\mathrm{I}_{\mathrm{u}}(\mathrm{z}) \mathrm{U}(\mathrm{z})\right)^{2}$

Assumption 3: $\sigma_{\mathrm{u}}{ }^{2} \approx{\sigma_{\mathrm{v}}}^{2} \approx{\sigma_{\mathrm{w}}}^{2}$, which yields:

$\mathrm{k}(\mathrm{z})=\frac{3}{2}\left(\mathrm{I}_{\mathrm{u}}(\mathrm{z}) \mathrm{U}(\mathrm{z})\right)^{2}$

In summary, the relationship between the turbulent kinetic energy $k$, the longitudinal turbulence intensity $I_{u}$ and the wind speed $U$ is given by:

$\mathrm{k}(\mathrm{z})=\mathrm{a}\left(\mathrm{I}_{\mathrm{u}}(\mathrm{z}) \mathrm{U}(\mathrm{z})\right)^{2}$

with a equal to $0.5,1$ or 1.5 . These different values for a have been used and/or mentioned in CFD studies in the past (e.g. Tominaga et al. 2008, van Hooff and Blocken 2010a, van Hooff et al. 2011, Blocken et al. 2012).

Note that the best practice guidelines by Tominaga et al. (2008) suggest to use a $=1$. In the present study, the three values are tested in order to evaluate the effects of physical diffusion. Note however that a is taken equal to 1 for the validation cases. Eq. (7) describes the vertical profile of the turbulence dissipation rate $\varepsilon$ :

$\varepsilon(\mathrm{z})=\frac{\mathrm{u}^{* 3}}{\kappa\left(\mathrm{z}+\mathrm{z}_{0}\right)}$

The specific dissipation rate $\omega$ is derived from $\mathrm{k}$ and $\varepsilon$ through Eq. (8), where $\mathrm{C}_{\mu}$ is an empirical constant taken equal to 0.09 :

$\omega(\mathrm{z})=\frac{\varepsilon(\mathrm{z})}{\mathrm{C}_{\mu} \mathrm{k}(\mathrm{z})}$

On the ground surface, a rough-wall boundary condition is imposed to include the effects of the upstream roughness on the development of the flow. The standard wall functions by Launder and Spalding (1974) with 
roughness modification by Cebeci and Bradshaw (1977) are used. The roughness parameters, i.e. the equivalent sand-grain roughness height $\left(\mathrm{k}_{\mathrm{s}}\right)$ and the roughness constant $\left(\mathrm{C}_{\mathrm{s}}\right)$, are determined from the aerodynamic roughness length $\mathrm{z}_{0}$ according to the relation derived by Blocken et al. (2007a, 2007b). For Fluent 6.3, this relationship is:

$\mathrm{k}_{\mathrm{S}}=\frac{9.793 z_{0}}{\mathrm{C}_{\mathrm{s}}}$

Note however that $\mathrm{k}_{\mathrm{S}}$ should be smaller than the height of the centroid of the wall-adjacent cells from the wall. Thus, the parameters $\mathrm{k}_{\mathrm{S}}$ and $\mathrm{C}_{\mathrm{S}}$ depend on the computational grid defined for each case, which is slightly different between configuration 1 and configuration 2 . The corresponding values of the computational parameters are then $\mathrm{k}_{\mathrm{s}}=0.28 \mathrm{~mm}$ and $\mathrm{C}_{\mathrm{s}}=0.874$ for configuration 1 and $\mathrm{k}_{\mathrm{s}}=0.4 \mathrm{~mm}$ and $\mathrm{C}_{\mathrm{s}}=0.612$ for configuration 2 . Note that these values are slightly different because of the slightly different near-wall grid resolutions. However, only the product $\mathrm{k}_{\mathrm{S}} \mathrm{C}_{\mathrm{S}}$ appears in the fully rough version of the wall-function roughness modification (Cebeci and Bradshaw 1977, Blocken et al. 2007b), therefore the individual values of $k_{S}$ and $C_{S}$ are not important, as long as the product satisfies Eq. (9). At the top and lateral sides of the domain, symmetry boundary conditions are applied to impose zero normal velocity and zero normal gradients of all variables. At the outlet side of the domain, a zero static pressure condition is prescribed. Standard wall functions with $\mathrm{k}_{\mathrm{S}}=0$ (smooth walls) are applied for all the building surfaces. The dimensionless wall unit $\mathrm{y}^{*}$ on grid $\mathrm{C}$ is generally below 10 at the building walls, but reaches a maximum value of 20 at the corners and inlet and outlet openings.

Careful selection of the inlet profiles and the roughness parameters $\mathrm{k}_{\mathrm{S}}$ and $\mathrm{C}_{\mathrm{S}}$ according to the consistency equation (Eq. (9)) is important to reduce unintended streamwise gradients in the flow profiles in the simulation, i.e. unintended changes between the inlet profiles and the incident profiles. The incident profiles are defined as those that would occur at the building position, if the building would be absent. To assess the unintended streamwise gradients, a simulation has been made in an empty domain, following the guidelines by Blocken et al. (2007a, 2007b, 2008a). Figure 4 shows, for different values of a in Eq. (6), the differences between the inlet and the incident profiles. The differences remain very limited for the mean wind speed $\mathrm{U}$, while they are larger for the turbulent kinetic energy, especially near the ground surface. These differences are the result of a limited degree of inconsistency between turbulence model, inlet profiles, wall functions and computational grid (Blocken et al. 2007b). Note that these differences would have been more pronounced if the upstream length would have been set to $5 \mathrm{H}$ instead of $3 \mathrm{H}$. Anyway, it is important to note that the simulation results of crossventilation presented in the next sections are representative of the incident profiles, rather than of the inlet profiles. The reason is that the incident profiles are those to which the building model is really subjected (Blocken et al. 2008a).

\subsection{Solver settings}

The commercial code Fluent 6.3 (Fluent Inc. 2006) was used to solve the 3D steady RANS equations with the shear-stress transport (SST) k- $\omega$ turbulence model (Menter 1994). The SIMPLE algorithm was used for pressure-velocity coupling. Second-order discretisation schemes were used for the viscous terms of the governing equations. For the convection terms, either first-order or second-order discretisation schemes were used, to investigate the effects of numerical diffusion. For the same reason, either standard interpolation or second-order interpolation was used for pressure. In order to assess the convergence of the solution, both the scaled residuals and the streamwise wind speed in some selected points of the domain were monitored as a function of the number iterations, in accordance to the guidelines by Franke et al. (2007) and Tominaga et al. (2008). Convergence was obtained when the scaled residuals levelled off and reached a minimum of $10^{-6}$ for $\mathrm{x}^{-}$, $\mathrm{y}$ - and z-velocity, $10^{-5}$ for $\mathrm{k}$ and $10^{-4}$ for $\omega$ and continuity for Cases 1.05 and 1.10 and a minimum of $10^{-7}$ and $10^{-}$ ${ }^{8}$ for $\mathrm{x}$-velocity and $\mathrm{y}$ - and $\mathrm{z}$-velocity respectively, $10^{-7}$ for $\mathrm{k}$ and $\omega$ and $10^{-5}$ for continuity for Cases 2.05 and 2.10. The streamwise wind speed was also monitored in three selected points along the centreline of the openings, upstream of the inlet opening, in the centre of the model and downstream of the outlet opening. In all the cases tested, it was observed that the wind speed upstream the inlet opening was steady, while for some of them, a fluctuating wind speed was reported in the centre of the model and downstream the outlet opening. These observations corresponded to observations of oscillatory convergence as demonstrated by the variations in scaled residuals as a function of the number of iterations. Note that this occurred in spite of the applied steady RANS approach. Therefore, for all cases, the wind speed values were monitored over 10000 iterations and the results were sampled and averaged over the last 1000 iterations when necessary. 


\section{CFD simulations: results and validation with wind tunnel measurements}

For Case 1.10 and Case 2.10, the results from the CFD simulations are compared with the experimental data in terms of the streamwise wind speed ratio along the centreline of the openings and in terms of velocity-vector fields in the vertical centreplane. For Case 1.05 and Case 2.05, the comparison is only made in terms of the streamwise wind speed ratio, because PIV vector fields for these configurations were not available. The CFD simulations that are shown in the validation study are those that are considered most accurate. These are the results obtained on Grid C (see section 3), for the inlet profiles corresponding to $\mathrm{a}=1$ (which is considered the best choice, see Tominaga et al. (2008) and the previous study by Ramponi and Blocken (2012)), and those obtained with second-order discretisation schemes and second-order pressure interpolation. Note that the experimental velocity-vector fields in the immediate vicinity of the openings are not presented, because they are considered less reliable due to effects of shadows or reflections that might have produced uncertainties in the PIV measurements at these positions. Also the very high wind speed gradients in this area might have caused additional uncertainties in the PIV results. The CFD validation results are shown in Figs. 5, 6 and 7. The following observations are made:

- Case 1.10: Figure 5a shows a good agreement between the PIV and the CFD results. Note that some discrepancies are present near the inlet and outlet openings, but as mentioned before, the PIV results are less reliable here. Figure $5 \mathrm{~b}$ also shows a very good agreement between the PIV and the CFD velocityvector field in the vertical centreplane. Both the PIV and CFD results show a standing vortex with similar size and position, upstream of the building. Both results also show the downward directed flow in the inlet opening, the generally downward directed flow inside the building itself and the upward flow through the outlet opening. In addition, also the large separation area on the building roof is reproduced, although the recirculation area is larger with CFD than with PIV.

- Case 2.10: Figure 6a shows a somewhat less good agreement between PIV and CFD results. Figure 6b illustrates that several general characteristics of the flow are quite well reproduced by the CFD results, such as the downward directed flow through the inlet opening, the flow near the floor inside the building, and the upward directed flow through the outlet opening. However, the size and position of the upstream standing vortex in the experiments are not correctly reproduced by the CFD results. Also, the recirculation area inside the building is predicted to be lower in the CFD results than in the PIV results. This is also the reason for the differences in streamwise wind speed ratio along the centreline shown in Figure 6a. It is possible that the differences between PIV and CFD in the indoor airflow are related to the differences in the upstream flow, in particular to the absence of a clear upstream standing vortex in the CFD results.

- Case 1.05: Figure 7a shows a very good agreement between PIV and CFD results. Remarkably, not only the upstream, indoor and downstream streamwise wind speed ratios are predicted very well, but also the peak values inside the two ventilation openings.

- Case 2.05: Figure 7b finally shows a good agreement between PIV and CFD results. Although the flow inside the inlet ventilation opening is not well predicted, the agreement along the centreline inside the building and downstream of the building is quite good.

\section{CFD simulations: results and effects of physical and numerical diffusion}

\subsection{Effects of physical diffusion}

The effects of physical diffusion are analysed by variation of the parameter a in Eq. (6) for the inlet turbulent kinetic energy. Note that $\mathrm{a}=1$ is considered the best choice according to the best practice guidelines by Tominaga et al. (2008), and that this value also provided a generally good agreement with the PIV experiments, as shown in the previous section. The results are shown in Figures 8 to 11. The following observations are made:

- Figure 8 shows the effects of decreased $(\mathrm{a}=0.5)$ and increased $(\mathrm{a}=1.5)$ physical diffusion on the streamwise wind speed ratio along the centreline for Cases 1.05 and 1.10. While the effects on the outdoor streamwise wind speed along the centreline, upstream and downstream of the ventilation openings, seem to be quite limited, the effects on the indoor air speed along the centreline are large. The increase of the physical diffusion in this area of low air speed leads to higher indoor air speed values along the centreline. The effects are similar for both cases.

- Figure 9 shows the effects of physical diffusion on the wind-velocity pattern directly upstream and downstream of the inlet ventilation opening for Case 1.10. This figure shows that the increased physical diffusion influences the size of the standing vortex, where the size of this vortex decreases with increased physical diffusion. This is an illustration of the fact that increased diffusion tends to "smoothen" 
gradients in the flow and suppress smaller and low-velocity flow features. Figure 9 also shows that the direction of the flow through the inlet ventilation opening is affected, with a less downward flow for increased physical diffusion. This is attributed to the differences in the outdoor upstream flow pattern. On the other hand, Figure 9 also shows that the jet entering the building is wider with increasing physical diffusion. This is attributed to two reasons: (1) the direction of the flow, which is more horizontal for larger physical diffusion, and (2) the larger physical diffusion itself, which causes a spreading of the jet. These differences in the jet characteristics explain the differences along the centreline shown in Figure 8.

- Figure 10 shows results for Cases 2.05 and 2.10. As opposed to the previous cases, the effects of physical diffusion on the streamwise wind speed along the centreline are much less pronounced. This can be explained by focusing on the wind-velocity pattern in Figure 11.

- Figure 11 shows clear differences in the predictions of the upstream standing vortex, in line with the observations in Figure 9. As opposed to the cases in Figures 8 and 9, these upstream differences give rise to only relatively small differences in the orientation of the jet that enters the building. However, the increasing physical diffusion does cause the indoor jet to get wider. This explains the somewhat larger indoor streamwise wind speed ratios along the centreline, as shown in Figure 10.

\subsection{Effects of numerical diffusion}

Substantial amounts of numerical diffusion are associated with the use of low-resolution grids and with the use of first-order accurate discretisation schemes. The effects of numerical or "artificial" diffusion are similar to those of physical diffusion. The effect of numerical diffusion due to lower-resolution grids was already shown in Figure 3, for Case 1.10. In addition, Figure 12 shows the effects of numerical diffusion due to first-order instead of second-order discretisation schemes and standard instead of second-order pressure interpolation. The impact on the streamwise wind speed ratio along the centreline is shown for the four cases. The results show that the effects of numerical diffusion on the outdoor streamwise wind speed upstream of the inlet ventilation opening are small, but that the effects on the indoor streamwise wind speed and also on the outdoor streamwise wind speed downstream of the outlet opening are large to very large. These observations confirm the importance of using at least second-order accurate discretisation schemes, as recommended by best practice guideline documents (Roache et al. 1986, Freitas 1993, Casey and Wintergerste 2000, Franke et al. 2007, Tominaga et al. 2008).

\section{Discussion}

The present study has focused on validation of CFD simulations of coupled outdoor wind flow and indoor airflow for four different configurations of simple, isolated, single-zone buildings, and on the analysis of the effects of physical and numerical diffusion on cross-ventilation flow. The following limitations of the study are mentioned:

- The validation has only been performed for 3D steady RANS with the SST k- $\omega$ model for four configurations of isolated, single-zone buildings. Future studies should focus on the evaluation of different turbulence modelling approaches (RANS, DES and LES), different turbulence models, and also on different building configurations, including buildings in suburban and urban areas and multizone buildings.

- The same limitations hold for the effects of physical and numerical diffusion. It is expected that these effects will be at least equally, and probably even more important, for buildings in suburban and urban areas, which are dominated by high wind speed jets through passages between buildings (see e.g. Stathopoulos and Storms 1986, Stathopoulos and Wu 1995, To and Lam 1995, Blocken et al. 2007b, 2008a, 2008b) and by their interaction with building wakes.

- The present study has only focused on cross-ventilation. Future work should focus on the analysis of physical and numerical diffusion effects on single-side ventilation flow.

In spite of these limitations, it is important to mention that:

- To the best knowledge of the authors, this study is the first to focus in detail on the effects of physical and numerical diffusion for cross-ventilation flow.

- Knowing the effects of physical diffusion is very important, because there is no consensus in the scientific literature on how to extract turbulent kinetic energy profiles from the measured mean wind speed and turbulence intensity profiles. Tominaga et al. (2008) suggest using a parameter a $=1$, which, in the present study, has been shown to be a good choice. Further research is needed on the determination of turbulent kinetic energy profiles from mean wind speed and turbulence intensity. 
- Knowing the effects of numerical diffusion is also very important, because computational grids for suburban and urban configurations are often highly unstructured grids, on which convergence can only be obtained by introducing sufficient numerical (artificial) diffusion by the use of first-order discretisation schemes. Clearly, this approach is counter-advised, and focus should be placed on the generation of high-resolution and high-quality grids on which convergence can be obtained with second -order discretisation schemes. A further discussion on this matter has been provided by Blocken et al. (2012).

\section{Summary and conclusions}

This paper has presented CFD simulations of wind-induced cross-ventilation of buildings. The 3D steady Reynolds-Averaged Navier-Stokes (RANS) approach was employed with the SST k- $\omega$ model to provide closure. The CFD simulations were coupled simulations, in which the outdoor wind flow and the indoor airflow have been solved simultaneously and within the same computational domain. The simulations have focused on four different configurations of simple, generic, isolated, single-zone buildings. The intention of the paper was twofold: (1) to provide a validation study of such coupled outdoor wind flow and indoor airflow simulations by comparison with detailed Particle Image Velocimetry (PIV) measurements in an atmospheric boundary layer wind tunnel; (2) to provide information on the effects of physical and numerical diffusion on the cross-ventilation flow in these four building configurations. First, the effect of physical diffusion was analysed by changing the inlet profiles of turbulent kinetic energy within a realistic range. Second, the effect of numerical diffusion was investigated by changing the grid resolution and by applying both first-order and second-order discretisation schemes. The results of the validation study showed a good to very good agreement for three of the four configurations, while a somewhat less good agreement was obtained for the fourth configuration. The results of the diffusion study showed that the effects of physical and numerical diffusion were very similar. Along the centreline between the openings, these effects were most pronounced inside the building, and less pronounced outside the building. The velocity-vector fields however showed that increased physical and numerical diffusion decreased the size of the upstream standing vortex and increases the spread of the jet entering the buildings. It was concluded that diffusion is an important transport mechanism in cross-ventilation of buildings, and that special care is needed to select the right amount of physical diffusion and to reduce the numerical diffusion, by using high-resolution grids and by using at least second-order accurate discretisation schemes.

\section{Acknowledgement}

The authors are very grateful to Professor Yukio Tamura of Tokyo Polytechnic University for his willingness to act as Editor for this paper and for his excellent management of the review process.

\section{References}

ASME, 2011. http://journaltool.asme.org/Templates/JFENumAccuracy.pdf. Retrieved on 30 July 2011.

Blocken, B., Carmeliet, J., Stathopoulos, T., 2007a. CFD evaluation of the wind speed conditions in passages between buildings - effect of wall-function roughness modifications on the atmospheric boundary layer flow. J. Wind Eng. Ind. Aerodyn. 95(9-11), 941-962.

Blocken, B., Stathopoulos, T., Carmeliet, J., 2007b. CFD simulation of the atmospheric boundary layer: wall function problems. Atmos. Environ. 41(2), 238-252.

Blocken, B., Stathopoulos, T., Carmeliet, J., 2008a. Wind environmental conditions in passages between two long narrow perpendicular buildings. J. Aerospace Eng.-ASCE 21(4), 280-287.

Blocken, B., Moonen, P., Stathopoulos, T., Carmeliet, J., 2008b. A numerical study on the existence of the Venturi-effect in passages between perpendicular buildings. J. Eng. Mech.-ASCE 134(12), 1021-1028.

Blocken, B., Janssen, W.D., van Hooff, T., 2012. CFD simulation for pedestrian wind comfort and wind safety in urban areas: General decision framework and case study for the Eindhoven University campus. Environ. Modell. Softw. 30: 15-34.

Caciolo, M., Stabat, P., Marchio, D., 2012. Numerical simulation of single-sided ventilation using RANS and LES and comparison with full-scale experiments. Build. Environ. 50: 202-213.

Casey, M., Wintergerste, T., 2000. ERCOFTAC special interest group on quality and trust in industrial CFD: best practices guidelines. European Research Community on Flow, Turbulence and Combustion 2000.

Cebeci, T., Bradshaw, P., 1977. Momentum transfer in boundary layers. Hemisphere Publishing Corp, New York. 
Chen, Q., 2009. Ventilation performance prediction for buildings: A method overview and recent applications. Build. Environ. 44(4), 848-858.

Evola, G., Popov, V., 2006. Computational analysis of wind driven natural ventilation in buildings. Energy Build 38(5), 491-501.

Fluent Inc., 2006. Fluent 6.3 User's Guide. Fluent Inc., Lebanon.

Franke, J., Hellsten, A., Schlünzen, H., Carissimo, B., 2007. Best practice guideline for the CFD simulation of flows in the urban environment.

Freitas, C.J., 1993. Journal of fluids engineering editorial policy statement on the control of numerical accuracy. ASME - J Fluids Eng 115, 339-40.

Heiselberg, P., Li, Y., Andersen, A., Bjerre, M., Chen, Z., 2004. Experimental and CFD evidence of multiple solutions in a naturally ventilated building. Indoor Air 14, 43-54.

Hu, C.H., Ohba, M., Yoshie, R. 2008. CFD modelling of unsteady cross ventilation flows using LES. J. Wind Eng. Ind. Aerodyn. 96, 1692-706.

Hunt, G.R., Linden, P.F., 1999. The fluid mechanics of natural ventilation - displacement ventilation by buoyancy-driven flows assisted by wind. Build. Environ. 34(6), 707-720.

Jiang, Y., Alexander, D., Jenkins, H., Arthur, R., Chen, Q., 2003. Natural ventilation in buildings: measurement in a wind tunnel and numerical simulation with large-eddy simulation. J. Wind Eng. Ind. Aerodyn. 91, 33153.

Jiang, Y., Chen, Q., 2002. Effect of fluctuating wind direction on cross natural ventilation in buildings from large eddy simulation. Build Environ 37, 379-86.

Karava, P., 2008. Airflow prediction in buildings for natural ventilation design: Wind tunnel measurements and simulation. Ph.D.Thesis; Department of Building, Civil and Environmental Engineering, Concordia University, Montreal Quebec.

Karava, P., Stathopoulos, T. 2011. Wind-induced internal pressures in buildings with large façade openings. J. Eng. Mech.-ASCE. Doi:10.1061/(ASCE)EM.1943-7889.0000296.

Karava, P., Stathopoulos, T., Athienitis, A.K., 2011. Airflow assessment in cross-ventilated buildings with operable façade elements. Build. Environ. 46, 266-279.

Kato, S., Murakami, S., Mochida, A., Akabayashi, S., Tominaga, Y., 1992. Velocity-pressure field of cross ventilation with open windows analyzed by wind tunnel and numerical simulation. J. Wind Eng. Ind. Aerodyn. 44, 2575-2586.

Kobayashi, T., Sandberg, M., Kotani, H., Claesson, L., 2010. Experimental investigation and CFD analysis of cross-ventilated flow through single room detached house model. Build. Environ. 45(12), 2723-2734.

Larsen, T.S., Heiselberg, P., 2008. Single-sided natural ventilation driven by wind pressure and temperature difference. Energy Build. 40(6), 1031-1040.

Launder, B.E., Spalding, D.B., 1974. The numerical computation of turbulent flows. Comput. Method Appl. M 3, 269-289.

Li ,Y.G., Delsante, A., 2001. Natural ventilation induced by combined wind and thermal forces. Build. Environ. 36(1), 59-71.

Linden, P.F., 1999. The fluid mechanics of natural ventilation. Annu. Rev. Fluid Mech. 31, 201-238.

Menter, F.R., 1994. Two-equation eddy-viscosity turbulence models for engineering applications. AIAA J. 32: 1598-605.

Meroney, R.N., 2009. CFD prediction of airflow in buildings for natural ventilation. Proceedings 11th Americas Conference on Wind Engineering, San Juan, Puerto Rico, pp. 1-11.

Mochida, A., Yoshino, H., Miyauchi, S., Mitamura, T., 2006. Total analysis of cooling effects of crossventilation affected by microclimate around a building. Sol. Energy 80, 371-82.

Mochida, A., Yoshino, H., Takeda, T., Kakegawa, T., Miyauchi, S., 2005;Methods for controlling airflow in and around a building under cross-ventilation to improve indoor thermal comfort. J. Wind Eng. Ind. Aerodyn. 93, 437-49.

Murakami, S., Kato, S., Ooka, R., Shiraishi, Y., 2004. Design of a porous-type residential_building model with low environmental load in hot and humid Asia. Energ. Build. 36(12): 1181-1189.

Nikas, K.S., Nikolopoulos, N., Nikolopoulos, A., 2010. Numerical study of a naturally cross-ventilated building. Energ. Build. 42, 422-34.

Norton, T., Grant, J., Fallon, R., Sun, D.W., 2010. Optimising the ventilation configuration of naturally ventilated livestock buildings for improved indoor environmental homogeneity. Build Environ 45, 983-995.

Ramponi, R., Blocken, B., 2012. CFD simulation of cross-ventilation for a generic isolated building: impact of computational parameters. Build. Environ. 53, 34-48.

Roache, P.J., Chia, K.N., White, F., 1986. Editorial policy statement on the control of numerical accuracy. J. Fluids Eng. 108, 2. 
Seifert, J., Li, Y., Axley, J., Rösler, M., 2006. Calculation of wind-driven cross ventilation in buildings with large openings. J. Wind Eng. Ind. Aerodyn. 94, 925-47.

Stavrakakis, G.M., Koukou, M.K., Vrachopoulos, M.G., Markatos, N.C., 2008. Natural cross-ventilation in buildings: Building-scale experiments, numerical simulation and thermal comfort evaluation. Energ. Build. 40(9), 1666-1681.

Stathopoulos, T., 1984. Design and fabrication of a wind tunnel for building aerodynamics. J. Wind Eng. Ind. Aerodyn. 16, 361-376.

Stathopoulos, T., Storms, R., 1986. Wind environmental conditions in passages between buildings. J. Wind Eng. Ind. Aerodyn. 24, 19-31.

Stathopoulos, T., Wu, H., 1995. Generic models for pedestrian-level winds in built-up regions. J. Wind Eng. Ind. Aerodyn. 54-55, 515-525.

Straw, M.P., Baker, C.J., Robertson, A.P., 2000. Experimental measurements and computations of the windinduced ventilation of a cubic structure. J. Wind Eng. Ind. Aerodyn. 88, 213-230.

Tablada, A., De Troyer, F., Blocken, B., Carmeliet, J., Verschure H., 2009. On natural ventilation and thermal comfort in compact urban environments - the Old Havana case. Build Environ 44, 1943-1958.

To, A.P., Lam, K.M., 1995. Evaluation of pedestrian-level wind environment around a row of tall buildings using a quartile-level wind speed descripter. J. Wind Eng. Ind. Aerodyn. 54-55, 527-541.

Tominaga, Y., Mochida, A., Yoshie, R., Kataoka, H., Nozu, T., Yoshikawa, M., Shirasawa, T., 2008. AIJ guidelines for practical applications of CFD to pedestrian wind environment around buildings. J. Wind Eng. Ind. Aerodyn. 96(10-11), 1749-1761.

Evola, G., Popov, V., 2006. Computational analysis of wind driven natural ventilation in buildings. Energ. Build. 38, 491-501.

van Hooff, T., Blocken, B., 2010a. Coupled urban wind flow and indoor natural ventilation modelling on a highresolution grid: A case study for the Amsterdam ArenA stadium. Environ. Modell. Softw. 25(1), 51-65.

van Hooff, T., Blocken, B., 2010b. On the effect of wind direction and urban surroundings on natural ventilation of a large semi-enclosed stadium. Comput. Fluids 39, 1146-1155.

van Hooff, T., Blocken, B., Aanen, L., Bronsema, B., 2011. A venturi-shaped roof for wind-induced natural ventilation of buildings: wind tunnel and CFD evaluation of different design configurations. Build. Envrion. 46(9): 1797-1807.

Wright, N.G., Hargreaves, D.M., 2006. Unsteady CFD simulations for natural ventilation. Int. J. Vent. 5, 13-20. 
FIGURE CAPTIONS

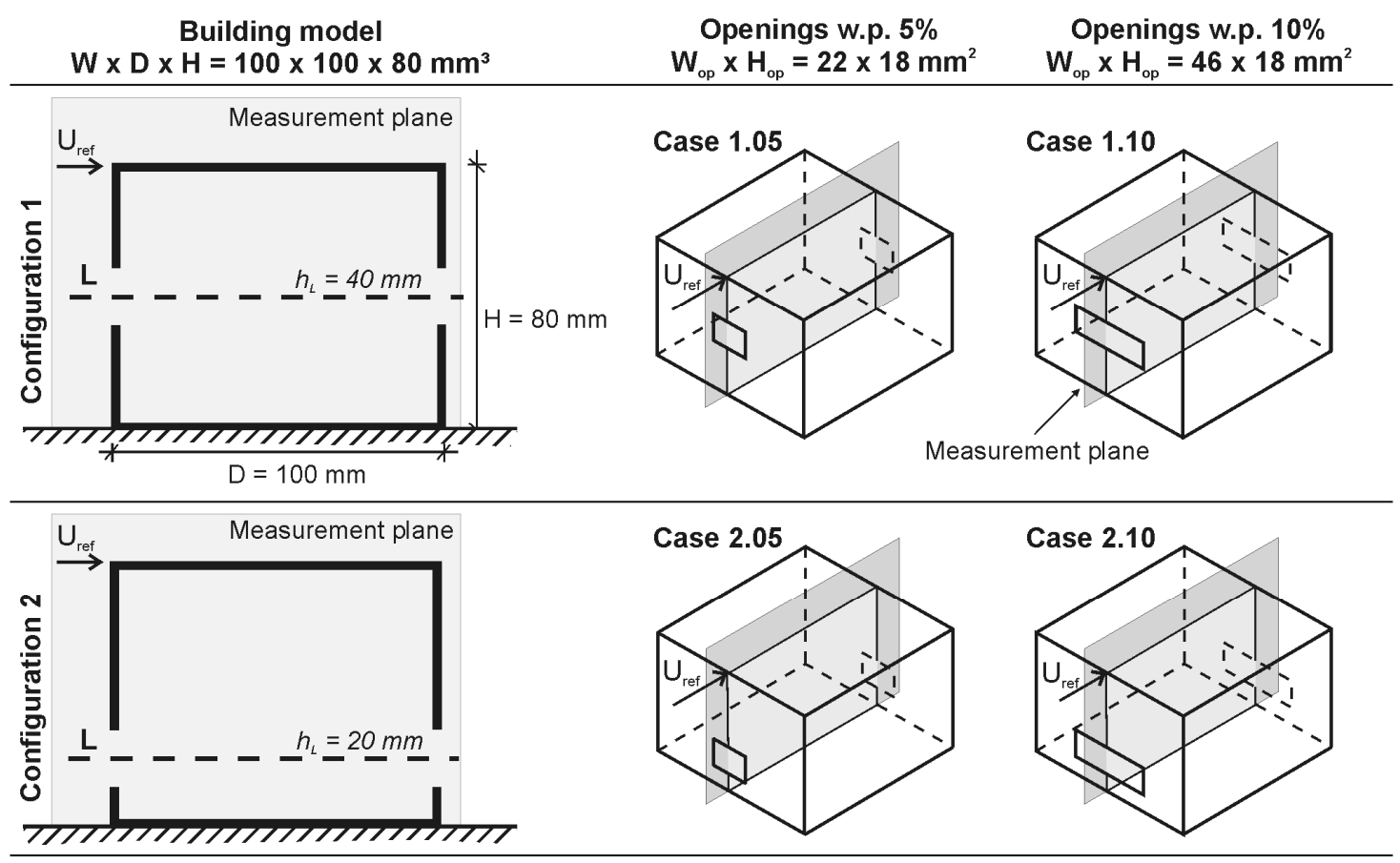

Fig. 1: Left: Vertical cross-section of the building models and position of the centreline ( $\mathrm{L}$ ) between the ventilation openings for configuration $1\left(\mathrm{~h}_{\mathrm{L}}=40 \mathrm{~mm}\right)$ and $2\left(\mathrm{~h}_{\mathrm{L}}=20 \mathrm{~mm}\right)$. Right: Opening size and vertical measurement plane for the cases analysed with wall porosity (w.p.) equal to 5\% (Case 1.05 and 2.05) and 10\% (Case 1.10 and 2.10).

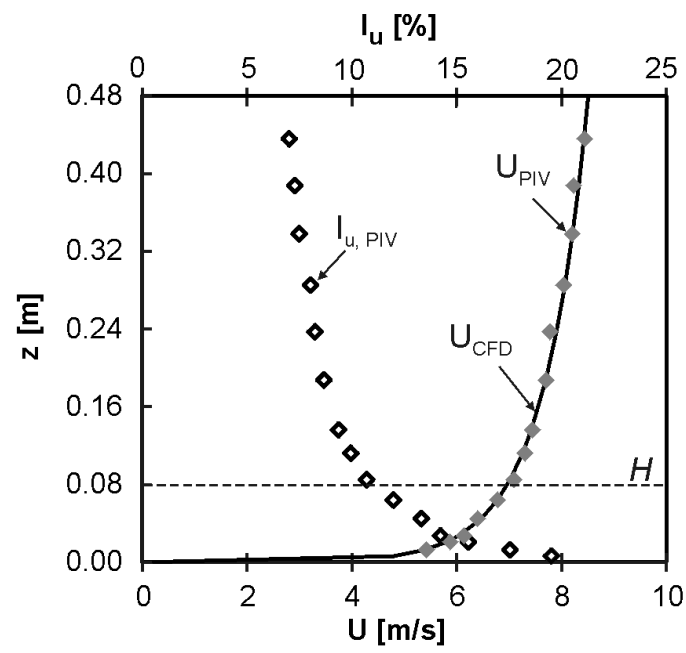

Fig. 2: Incident vertical profiles of mean wind speed $\left(\mathrm{U}_{\mathrm{PIV}}\right)$ and streamwise turbulence intensity $\left(\mathrm{I}_{\mathrm{u}, \mathrm{PIV}}\right)$ measured in the wind tunnel at the building position (Karava et al., 2011) and comparison with the logarithmic inlet profile of the mean wind speed $\left(\mathrm{U}_{\mathrm{CFD}}\right)$ used in the CFD simulations. 
(a)

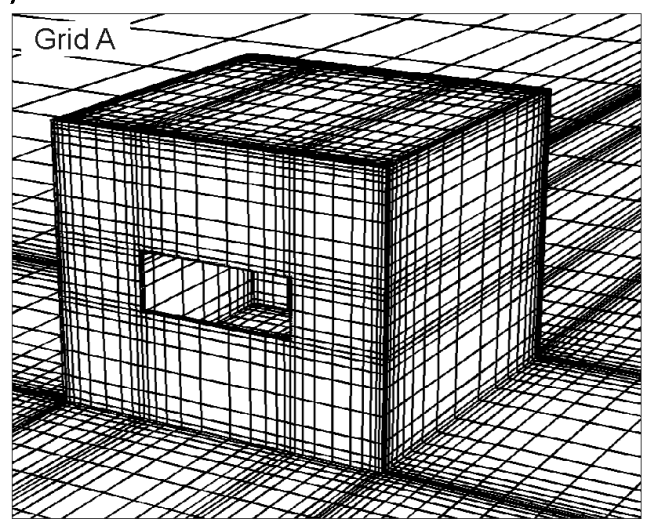

(c)

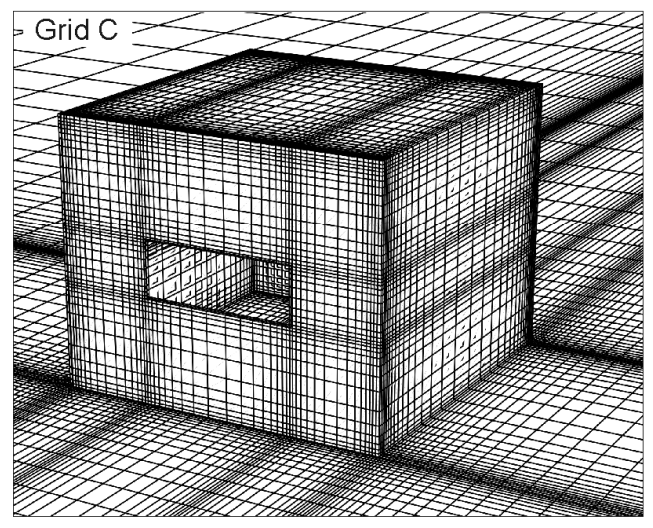

(b)
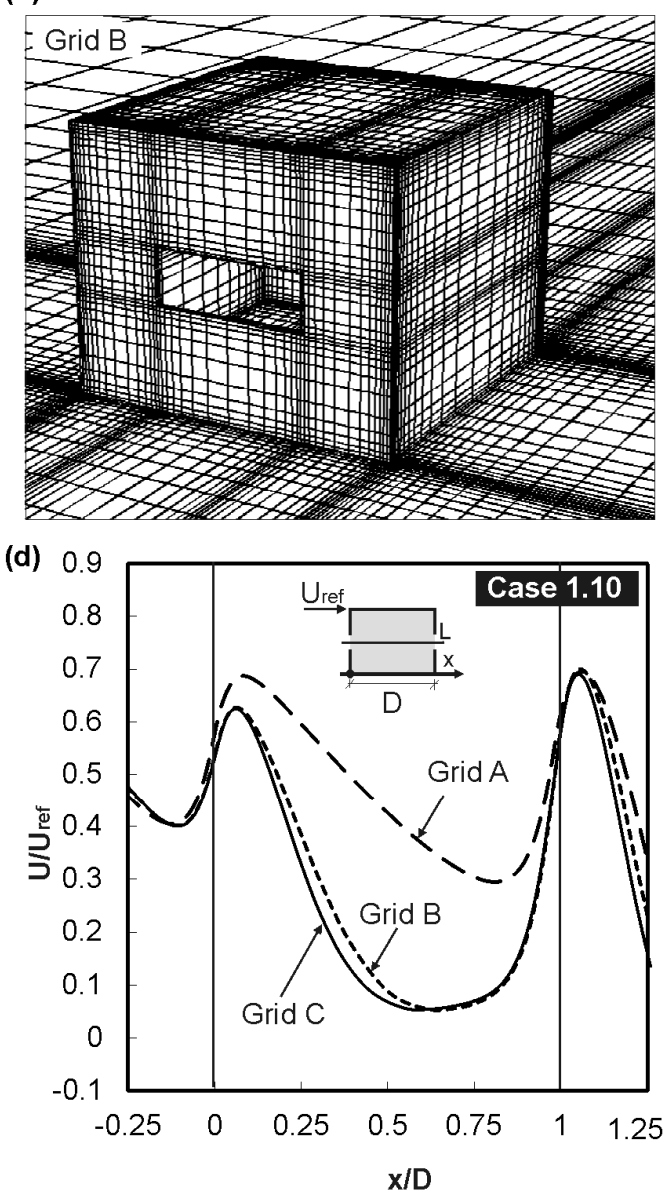

Fig. 3: Grid sensitivity analysis for Case 1.10: $(\mathrm{a}, \mathrm{b}, \mathrm{c})$ Computational grids obtained by refining with about a factor 2 from Grid A (a) - 144,696 cells, to Grid B (b) - 314,080 cells and Grid C (c) - 575,247 cells; (d) Comparison of the streamwise wind speed ratio $\left(\mathrm{U} / \mathrm{U}_{\mathrm{ref}}\right)$ along the centreline of the openings for the three grids. Based on this analysis, grid $\mathrm{C}$ was used for the simulations. 

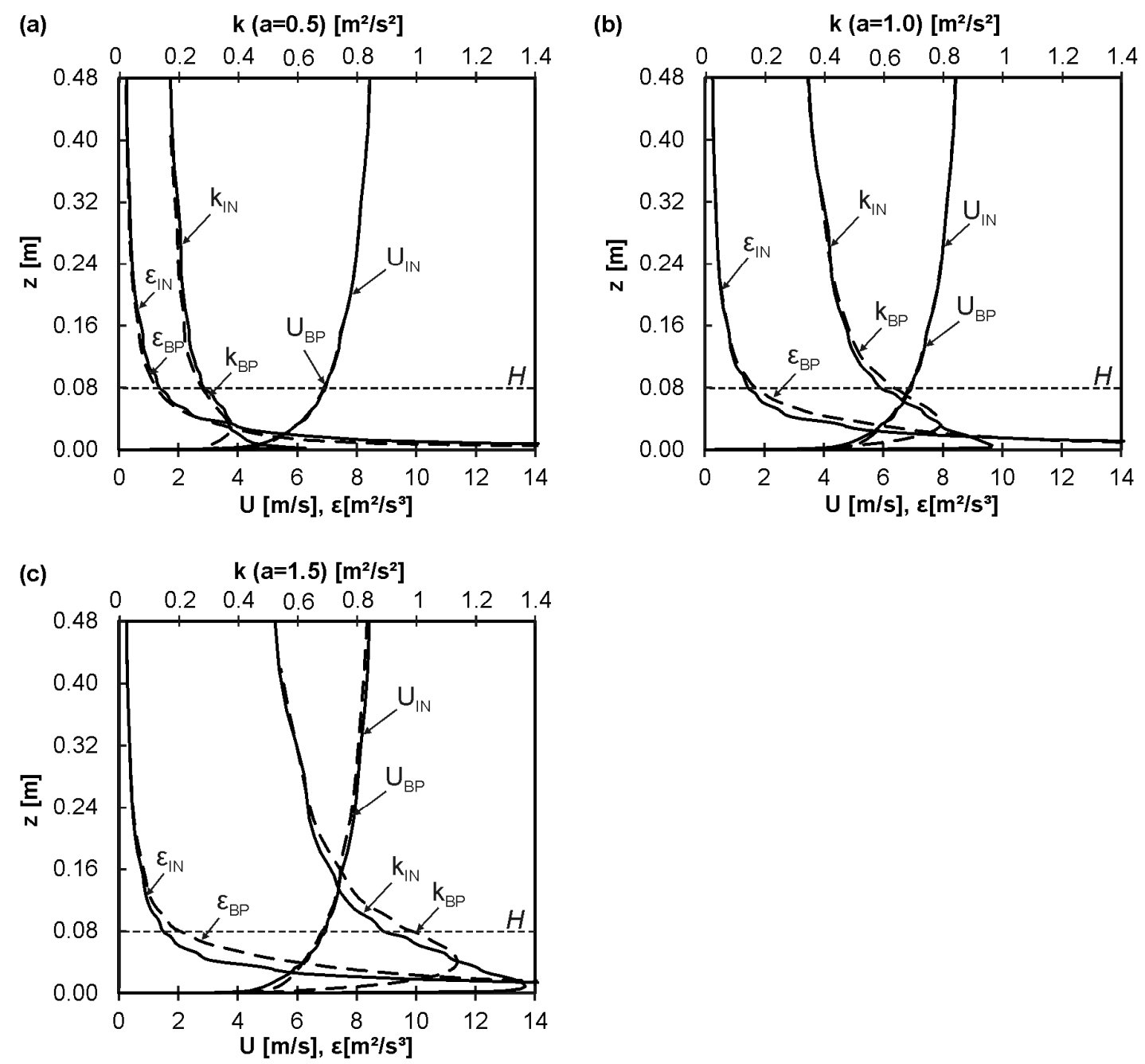

Fig. 4: Comparison of inlet profiles and incident profiles of mean wind speed (U), turbulent kinetic energy (k) and turbulence dissipation rate $(\varepsilon)$. The inlet profiles are those at the inlet of the domain (continuous line, subscript "IN"), the incident profiles are those at the building position (dashed line, subscript "BP"). Each figure corresponds to a different value of a in Eq. (6): (a) 0.5, (b) 1.0, (c) 1.5 . 

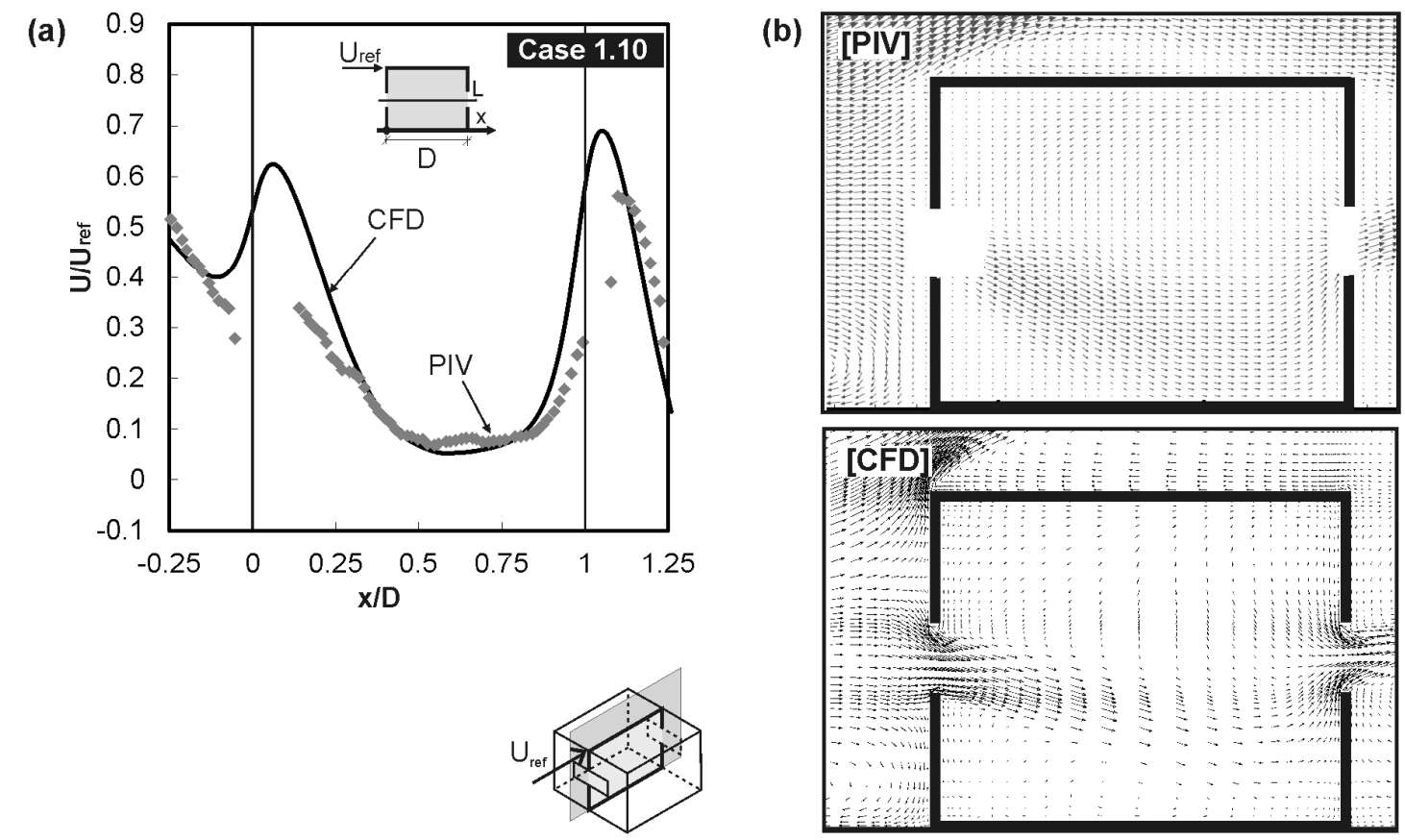

Fig. 5: Validation results for Case 1.10: comparison between the experimental (PIV) measurements and the numerical (CFD) results in terms of (a) streamwise wind speed ratio along the centreline and (b) velocity-vector field in the vertical centreplane.

(a)
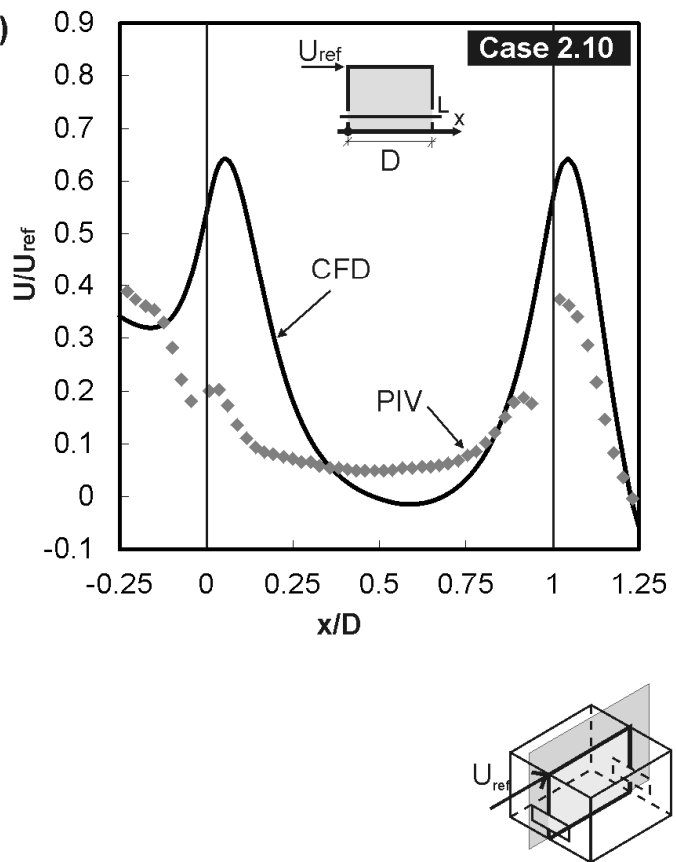

(b)
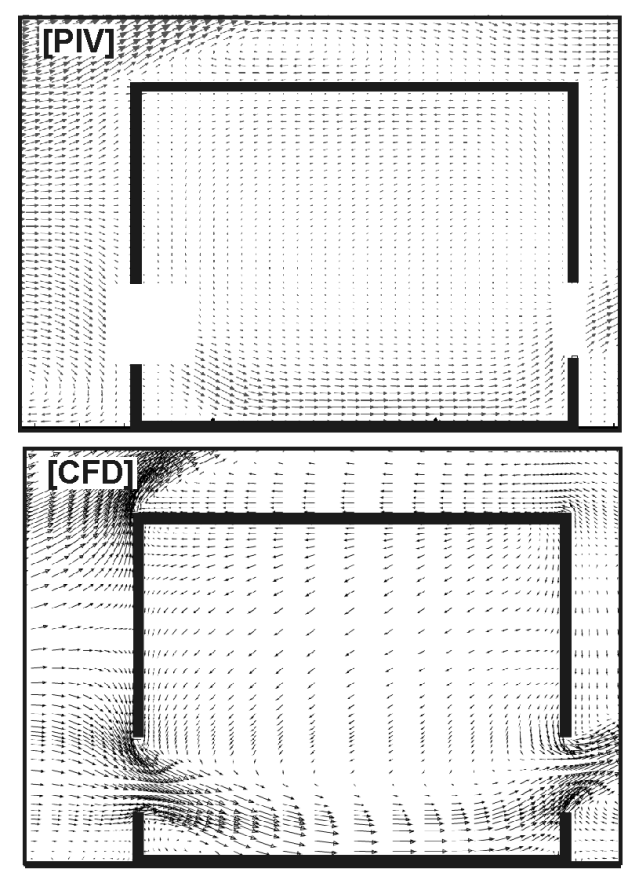

Fig. 6: Validation results for Case 2.10: comparison between the experimental (PIV) measurements and the numerical (CFD) results in terms of (a) streamwise wind speed ratio along the centreline and (b) velocity-vector field in the vertical centreplane. 
(a)

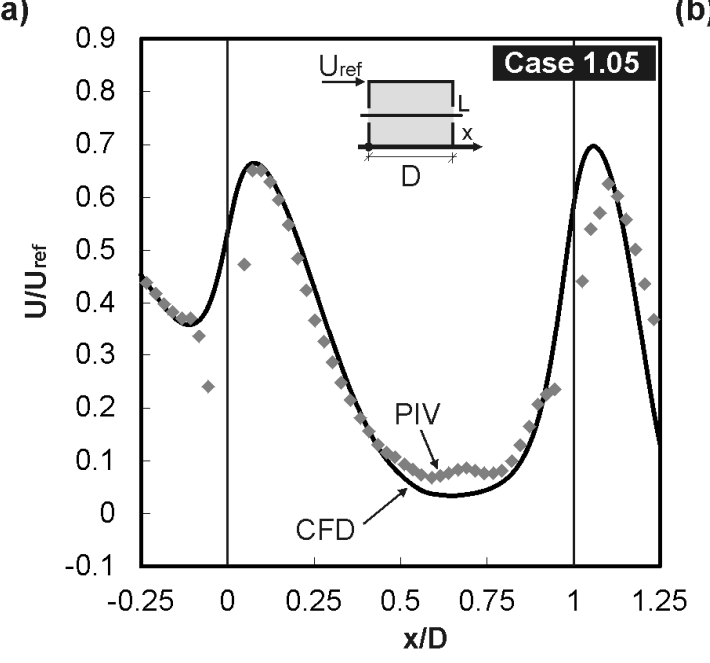

(b)

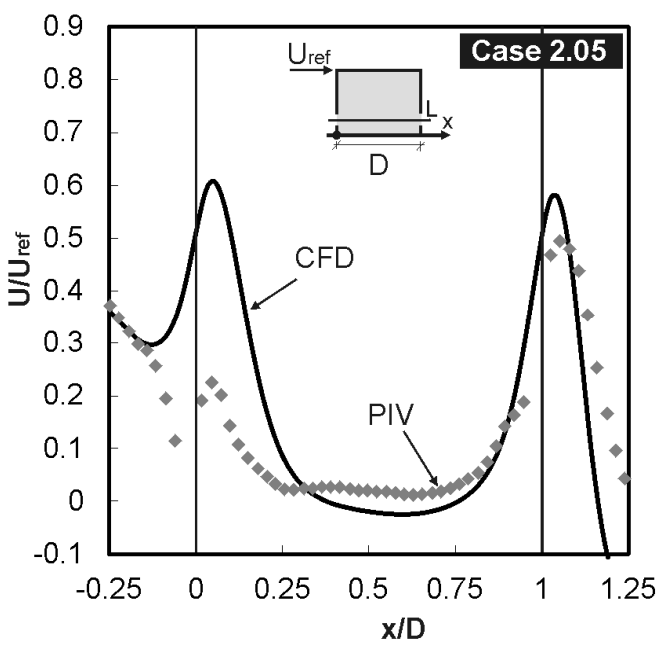

Fig. 7: Validation results for (a) Case 1.05 and (b) Case 2.05: comparison between the experimental (PIV) measurements and the numerical (CFD) results in terms of streamwise wind speed ratio along the centreline.

(a)

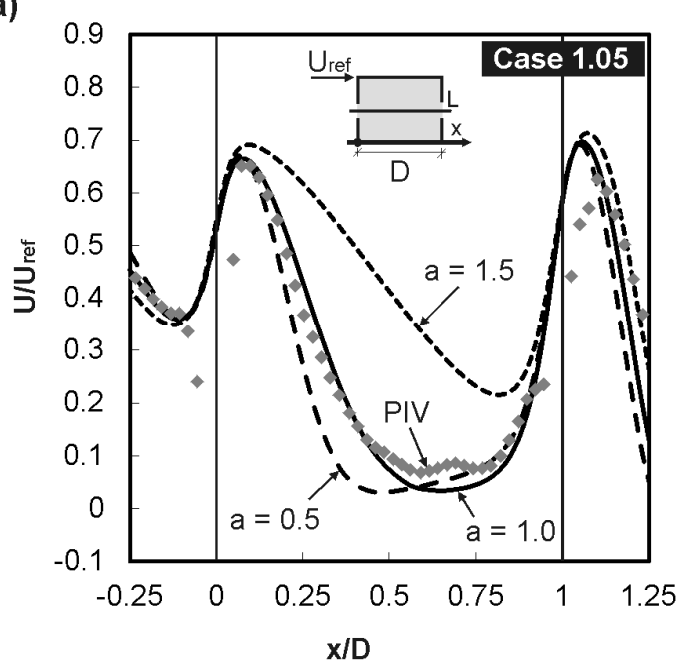

(b)

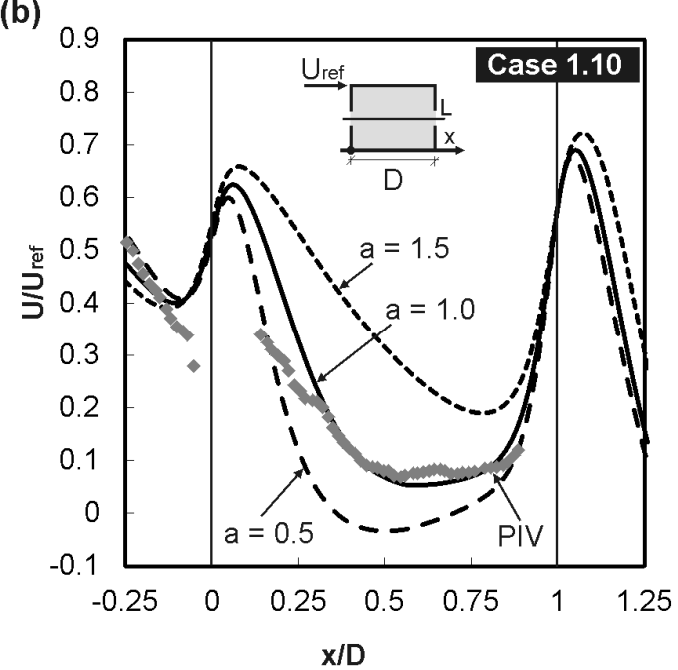

Fig. 8: Analysis of physical diffusion on the CFD results by variation of the parameter a in the inlet turbulent kinetic energy profile for (a) Case 1.05 and (b) Case 1.10: Comparison between the streamwise wind speed ratios along the centreline. 


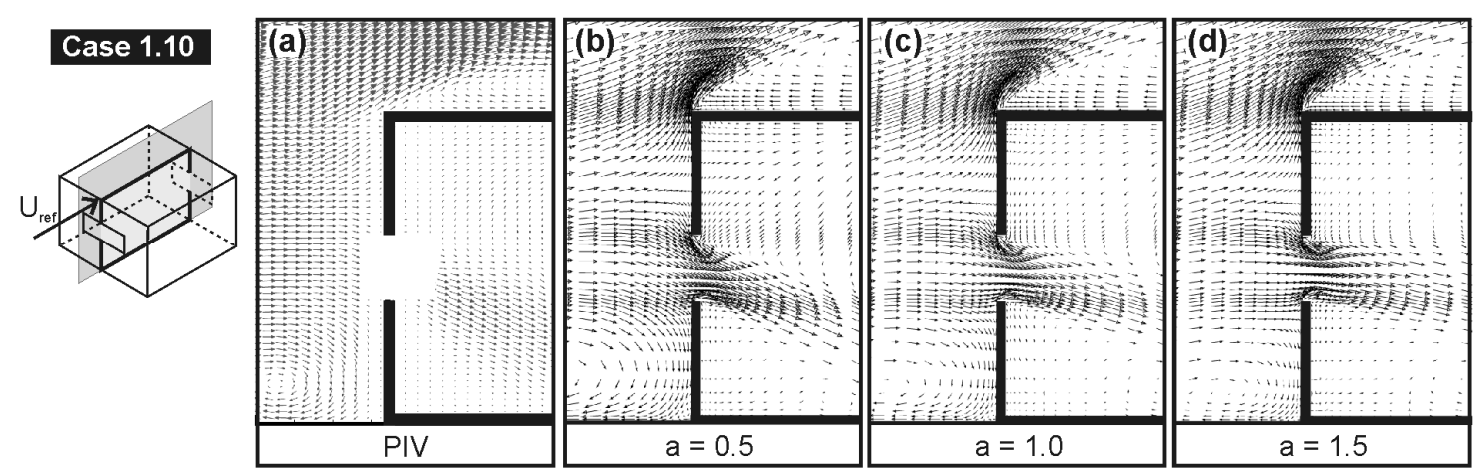

Fig. 9: Analysis of physical diffusion on the CFD results by variation of the parameter a in the inlet turbulent kinetic energy profile for Case 1.10: Comparison between velocity-vector fields in the vertical centreplane with (a) PIV and (b-d) CFD with parameter a equal to (b) 0.5 , (c) 1.0 and (d) 1.5 .

(a)

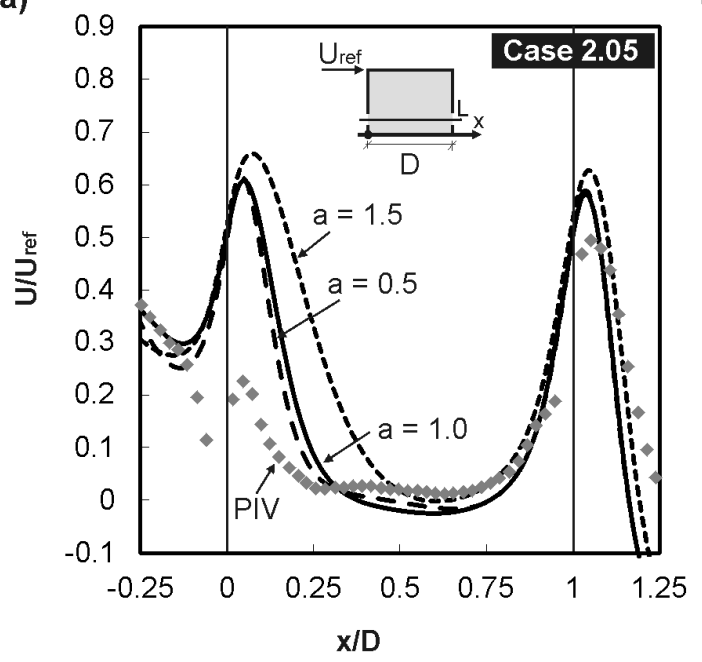

(b)

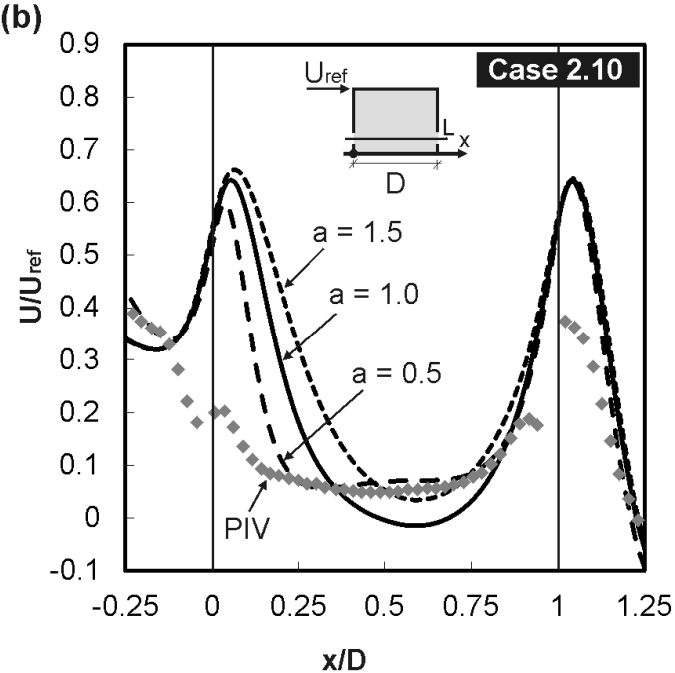

Fig. 10: Analysis of physical diffusion on the CFD results by variation of the parameter a in the inlet turbulent kinetic energy profile for (a) Case 2.05 and (b) Case 2.10: Comparison between the streamwise wind speed ratio along the centreline.

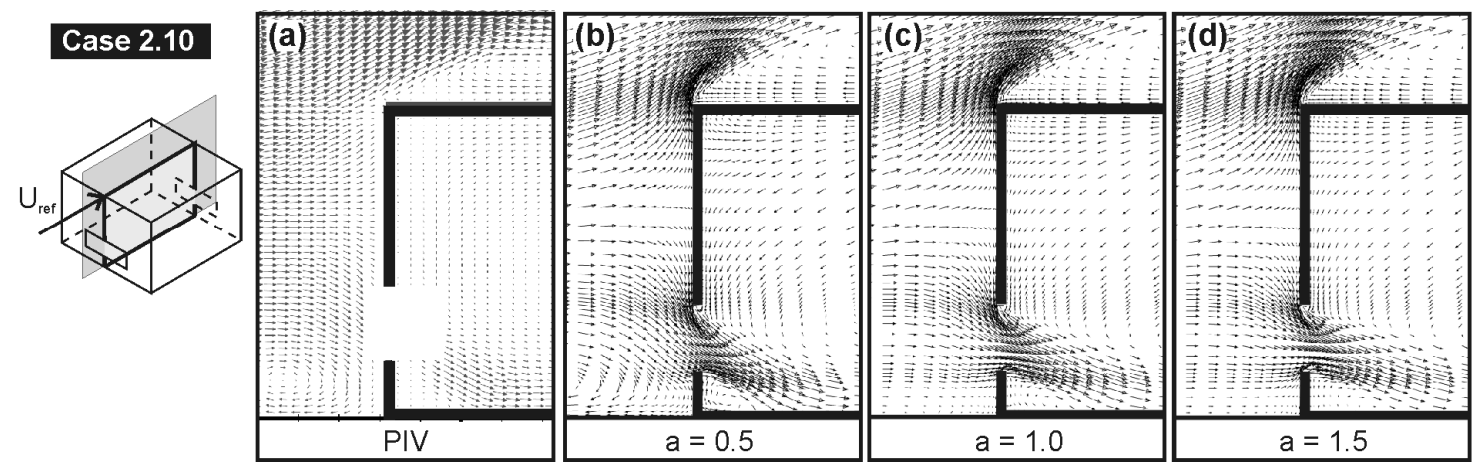

Fig. 11: Analysis of physical diffusion on the CFD results by variation of the parameter a in the inlet turbulent kinetic energy profile for Case 2.10: Comparison between the velocity-vector field in the vertical centreplane with (a) PIV and (b-d) CFD with parameter a equal to (b) 0.5 , (c) 1.0 and (d) 1.5 . 
(a)

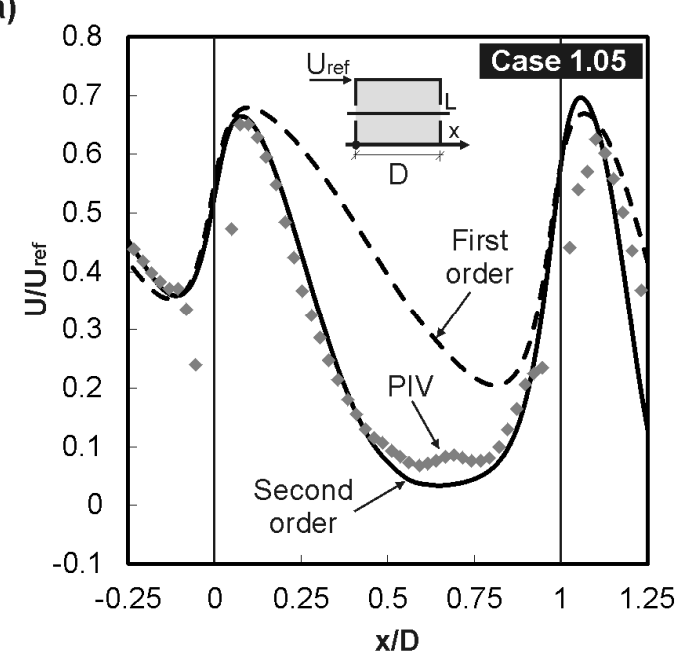

(c)

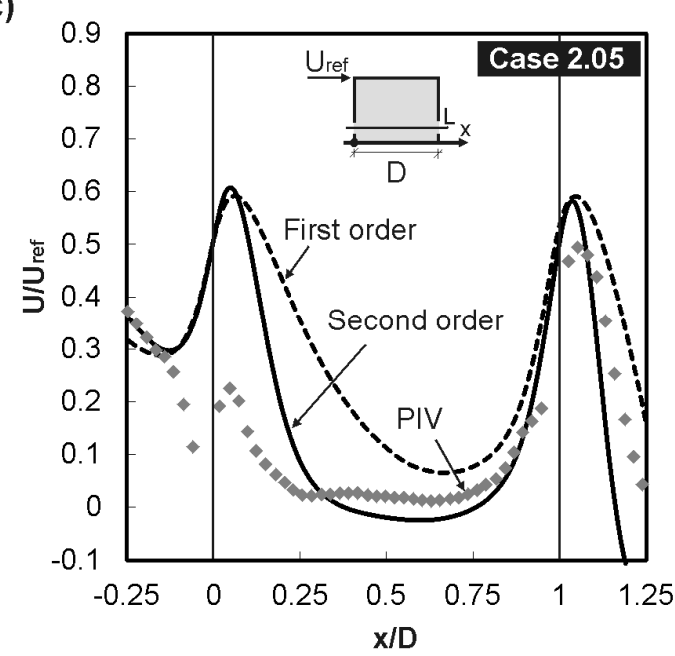

(b)

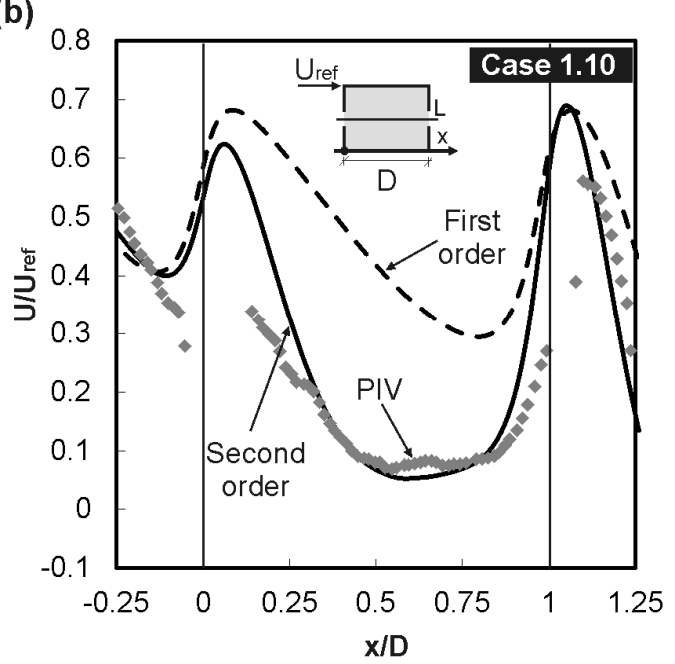

(d)

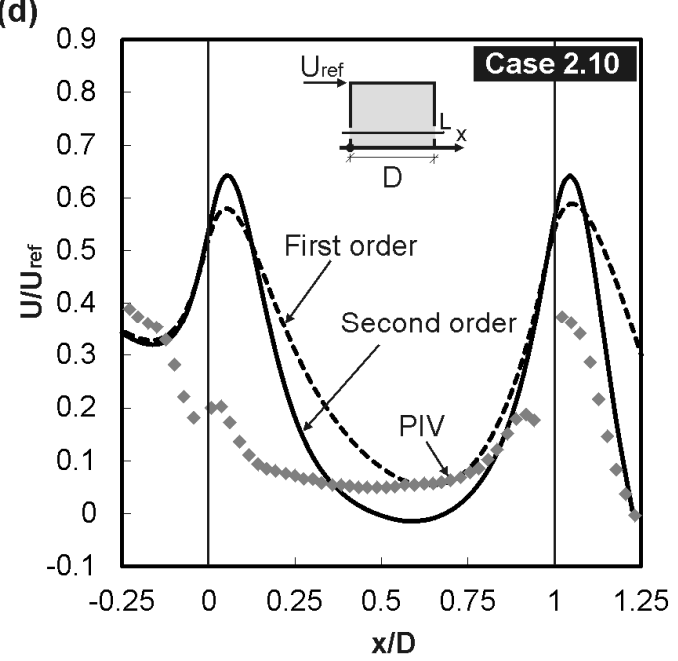

Fig. 12: Analysis of numerical diffusion on the CFD results (streamwise wind speed ratio along the centreline) by variation of the discretisation and pressure interpolation scheme for (a) Case 1.05; (b) Case 1.10; (c) Case 2.05 and (d) Case 2.10. 